\title{
Hydrodynamics influence coral performance through simultaneous direct and indirect effects
}

\author{
Hunter S. Lenihan, ${ }^{1,5}$ James L. Hench, ${ }^{2}$ Sally J. Holbrook, ${ }^{3,4}$ Russell J. Schmitt, ${ }^{3,4}$ and Matthew Potoski ${ }^{1}$ \\ ${ }^{1}$ Bren School of Environmental Science and Management, University of California, Santa Barbara, California 93106-5131 USA \\ ${ }^{2}$ Marine Laboratory, Nicholas School of the Environment, Duke University, 135 Marine Lab Road, Beaufort, \\ North Carolina 28516 USA \\ ${ }^{3}$ Department of Ecology, Evolution, and Marine Biology, University of California, Santa Barbara, California 93106-9610 USA \\ ${ }^{4}$ Coastal Research Center, Marine Science Institute, University of California, Santa Barbara, California 93106-6150 USA
}

\begin{abstract}
Hydrodynamic conditions can influence the distribution and abundance of aquatic species in many ways, including directly through disturbance and resource delivery, and indirectly by altering environmental cues and species interactions. In coral reef ecosystems, corallivory is an important top-down control of coral populations, while water motion can enhance coral performance via autotrophic and/or heterotrophic pathways. Using a large-scale field assay in Mo'orea, French Polynesia, we measured the extent to which the growth of a branching acroporid coral is influenced by hydrodynamics that deliver nutrients and food to corals but also impede corallivory. We explored two hydrodynamic properties that characterized our study system, mean current velocity and current velocity fluctuation (a measure of waves and turbulence). In treatments where predators were excluded, coral skeletal growth was positively related to mean current velocity, whereas no effect of velocity fluctuations was detected. In the presence of predators, growth was positively related to velocity fluctuations, but no relationship with mean velocity was detected. The major effect of velocity fluctuations was to reduce the attack rate of corallivores by lowering both their per capita bite rate and local density. Corals thus benefited directly from increased currents, probably through enhanced autotrophy and/or heterotrophy, and indirectly from velocity fluctuations through reduced corallivory. Our data indicate that for the coral and locale we examined, the indirect hydrodynamic effect on coral performance via reduction in corallivory was substantial, increasing daily growth rate by $4 \%$. Hydrodynamic enhancement of acroporid coral growth via simultaneous direct and indirect effects can be important for the persistence of coral reefs as well as their recovery following disturbance.
\end{abstract}

Key words: Acropora elseyi; coral reefs; corallivory; fish; hydrodynamics; indirect effects; Mo'orea, French Polynesia; predation; recovery; resilience; turbulence; waves.

\section{INTRODUCTION}

Coral reefs are highly complex and diverse ecosystems that provide critical ecosystem services but which are increasingly threatened by human activities (Aronson and Precht 1997, Mumby and Steneck 2008). On many reefs worldwide, the combination of stressors, including added nutrients from land-based activities, increased storm activity, predators, diseases, and over exploitation of herbivorous fishes, has elevated coral mortality and recruitment failure (Hughes 1994, De'ath et al. 2012). In some cases, this has caused persistent shifts from the original dominance by corals to dominance by macroalgae, a change that has degraded reef biodiversity and ecological functioning (Hughes et al. 2010). By contrast, some reef systems, predominantly those in the IndoPacific, appear resilient to disturbance even in the face of

Manuscript received 10 June 2014; revised 6 November 2014; accepted 10 November 2014. Corresponding Editor: R. B. Aronson.

55-mail: lenihan@bren.ucsb.edu multiple and recurrent natural perturbations, especially bleaching events, Acanthaster sea star outbreaks, and cyclones (Adjeroud et al. 2009, Adam et al. 2011, 2014). Such resilience is not surprising because coral reefs are dynamic, disturbance-driven systems that have evolved over millennia to withstand abiotic and biotic stress (Jackson 1992, Brown 1997). Identifying factors that promote coral reef resilience could advance our ability to conserve and manage reefs as impacts of climate change and other anthropogenic perturbations persist (Bellwood et al. 2004).

Reef-building scleractinian corals display substantial phenotypic (morphological, behavioral, and biochemical) and genetic plasticity in response to physical stress, allowing some species to inhabit areas impacted by powerful waves, low light, and heavy sedimentation (Brown 1997). Despite this plasticity, coral communities display spatial zonation driven partially by interspecific variation in resistance to hydrodynamic stress (Done 1982, Veron 2000, Aronson et al. 2005, Madin and Connolly 2006). For example, compact, thickly 
branched, or robust plating corals often occupy hydrodynamically exposed areas (e.g., outer shallow reef slopes). Massive, slow-growing corals can withstand high temperature, sediment loading, and low light levels, and so frequently dominate sheltered to semi-exposed habitats (e.g., fringing reefs). Delicate, highly branched, acroporid corals usually inhabit moderately exposed environments (e.g., at medium water depths on exposed reef slopes), where they have adapted through rapid growth, asexual reproduction, and other mechanisms (Jackson 1992). Similar patterns of coral community composition exist in lagoon environments (Lenihan et al. 2011). Of course, hydrodynamic conditions also benefit corals. For example, current velocity can increase the growth of coral colonies by improving mass transfer of gasses, nutrients, and metabolites across coral tissue (Jokiel 1978, Lesser et al. 1994, Falter et al. 2004), thus enhancing autotrophy (Sebens et al. 2003).

Biotic stressors that help determine patterns of coral abundance include disease, which can help set coral depth distributions (Aronson et al. 2005), and Acanthaster outbreaks, which can extirpate corals from reefs in the Indo-Pacific (Moran 1986). In addition to Acanthaster, there are $>50$ other species of invertebrate corallivores and $>100$ species of vertebrate (fish) corallivores that prey on corals (Rotjan and Lewis 2008) influencing their growth, survival, and species composition (Neudecker 1979, Glynn 1990, Hixon 1997). Corallivorous fish can impede coral recovery from natural perturbations (Rotjan et al. 2006), especially juvenile branching acroporid corals (Knowlton et al. 1990), which many corallivores favor (Cole et al. 2008). Several studies have identified abiotic conditions that influence corallivore-coral interactions, such as water depth (e.g., Miller and Hay 1998) and habitat structure (Wellington 1982, Littler et al. 1989, Lenihan and Edmunds 2010, Lenihan et al. 2011). Despite this substantial body of work, we still have a poor understanding of how abiotic conditions and biotic processes interact to determine the distribution and abundance of benthic organisms, especially in coral reef communities.

Here we test the hypothesis that the individual performance of juvenile branching acroporid corals is influenced directly by hydrodynamic conditions that enhance coral growth (e.g., through autotrophy and/or heterotrophy), and indirectly by limiting predation by corallivorous fish. If the relative influence of direct and indirect controls by hydrodynamic conditions can be identified, it has tremendous implications for conservation and management of reef-forming corals. This is especially true for highly branched corals that have major positive effects on reef biodiversity (Holbrook et al. 2003, 2011, Johnson et al. 2011). We used a largescale, multi-disciplinary field assay to explore direct and indirect effects of local heterogeneity in hydrodynamic conditions on growth of a common branching coral, Acropora elseyi, in lagoons of Mo'orea, French Poly- nesia, a system that has exhibited resilience to large natural perturbations in recent decades (Adam et al. 2011, 2014, Trapon et al. 2011). Populations of branching acroporid corals, which provide complex physical habitat and other ecosystem services, have recovered repeatedly in some habitats on Mo'orea and surrounding islands due apparently to consistent recruitment (Adjeroud et al. 2009) and strong top-down control of macroalgal competitors by herbivorous fish (Adam et al. 2011). Our study was designed to explore whether and how hydrodynamics enhance acroporid coral growth, and thus potentially recovery from disturbance, via effects on small juvenile colonies. We thus tested two specific hypotheses related to two hydrodynamic properties: coral skeletal growth increases with increasing current velocity and velocity fluctuations via (1) processes likely involving nutrient enrichment that influences colony growth, including mass transfer and/or delivery of zooplankton food, and (2) altered top-down control due to hydrodynamically reduced attack rates by corallivorous fish. Many ecological studies focus on mean velocity, or "flow," as a primary driver of physical-biological coupling despite waves and turbulence (i.e., velocity fluctuations) being recognized as having important ecological effects, including influencing predator-prey interactions (Powers and Kittinger 2002, Smee et al. 2010). Here we estimated both mean velocity and velocity fluctuations (related to waves and turbulence), to assess their separate effects on coral performance. Our results supply quantitative estimates of direct and indirect hydrodynamic mechanisms that mediate coral growth, information that has important implications for coral reef conservation, management, and perhaps restoration.

\section{Methods \\ Study site}

We conducted our study in Vaipahu Lagoon on the north shore of Mo'orea, French Polynesia $\left(17^{\circ} 30^{\prime} \mathrm{S}\right.$, $149^{\circ} 50^{\prime} \mathrm{W}$; see Plate 1$)$. As with many island reef systems, Mo'orea is exposed to offshore wave forcing that drives persistent across-reef hydrodynamic gradients. Waves breaking over the reef crest drive water motion on the reef flat in two ways. First, while much of the incident wave energy is dissipated by wave breaking, some wave energy continues to propagate across the reef at a range of wave frequencies. Second, in a timeaveraged sense, waves generate "set-up," which is a super-elevation of the water surface near the reef crest. Wave set-up generates an across-reef horizontal pressure gradient force that drives a mean current toward the reef flat and lagoon. Currents and waves are modified and attenuated across the reef by turbulent dissipation over the rough coral substrate (Rosman and Hench 2011, Hench and Rosman 2013). Thus offshore wave forcing and drag due to the coral substrate produce gradients in both mean and oscillatory flow on the back reef. This 


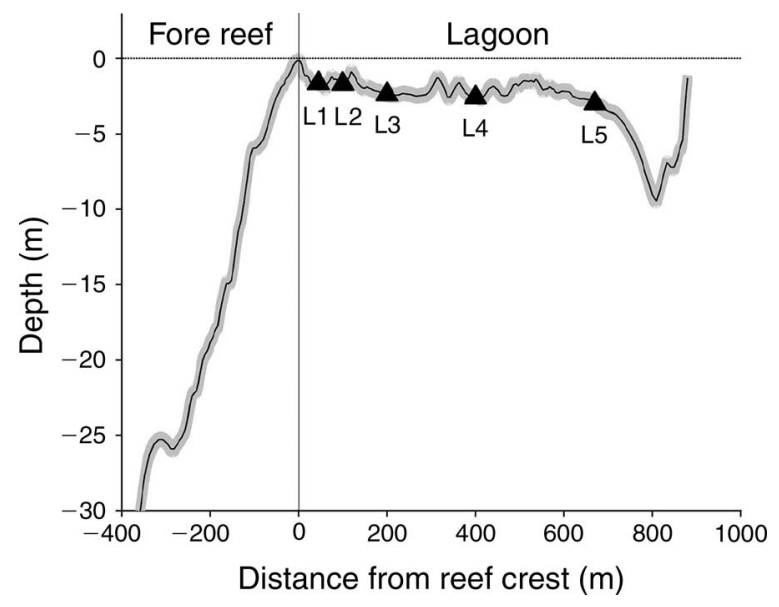

FIG. 1. A cross-section of the reef bathymetry, showing the location of the five study sites (L1-L5), the distance of the sites from the reef crest, and water depths. The scale of the horizontal, or $x$-axis, is greatly compressed. The predominant direction of the current within the lagoon is across the reef (left to right), driven primarily by waves breaking over the reef crest.

conceptual model has been previously studied in a number of reef flat systems (e.g., Hearn et al. 1999), including the field site examined here (Hench et al. 2008, Rosman and Hench 2011, Monismith et al. 2013).

The Vaipahu Lagoon floor is a patchy mosaic of substrata (coral rubble, sand, and basalt bottom) interspersed with coral colonies ranging from $<1 \mathrm{~cm}$ to $>3 \mathrm{~m}$ diameter. Mounding and massive corals (Porites spp.) are distributed across the three major lagoon habitats: back reef (adjacent to the barrier reef crest), mid-lagoon, and fringing reef (adjacent to shore). Juvenile and adult branching corals, predominantly Pocillopora and Acropora spp., are found in greatest abundance in the back reef (Lenihan et al. 2011). Mo'orea's lagoon supports relatively large populations of many corallivorous fishes, especially butterflyfishes (Chaetodon spp.; Chaetodontidae), spot-fin porcupinefish (Diodon hystrix; Diodontidae), white-spotted puffer (Arothron hispidus; Tetradontidae), and several species of triggerfish (Balistidae) (Brooks 2014). See Appendix A for further details about the lagoon habitats.

\section{Hydrodynamic measurements}

We explored the effects of hydrodynamics on growth of the branching coral Acropora elseyi at five lagoon sites located at increasing distances from the reef crest (sites L1-L5, Fig. 1). The sites were selected to permit simultaneous sampling across the hydrodynamic gradient and provide a framework to understand and quantify potential physical-biological interactions. We conducted hydrodynamic measurements so we could relate characteristics of hydrodynamic forcing to coral growth and corallivory. We focused on water motion that could influence the growth of corals through processes affecting gas exchange and the delivery of nutrients and food, and the ability of fish to successfully attack a coral. Velocity measurements were made simultaneously at our five study sites, sampling twice per second to resolve currents, waves, and large-scale turbulence. Measurements were made using upward-looking acoustic Doppler current profilers (ADCP; $2 \mathrm{MHz}$ Nortek Aquadopp; Nortek AS, Rud, Norway) deployed on the seafloor (Appendix B). The ADCPs also contained a temperature sensor that recorded near bottom temperatures at the same rate as velocity. To relate hydrodynamics to coral growth and corallivory, we computed the mean across-reef (i.e., horizontal) current velocity $(\bar{u})$ and a measure of velocity fluctuations in the form of a standard deviation of the across-reef velocity $\left(\sigma_{u}\right.$; units, $\left.\mathrm{cm} / \mathrm{s}\right)$. We focused our analyses on across-reef water motion, rather than along-reef and vertical motion, because it overwhelmingly dominated the hydrodynamic conditions for both the mean and variance in the observed velocities (Appendix B: Figs. B1, B2). The $\sigma_{u}$ is related to the variance in the instantaneous flow velocity as $\sigma_{u}=$ $\sqrt{\operatorname{var}(u)}$ and obtained from integration of the power spectra of velocity time series (Appendix B: Fig. B3A). We report velocity fluctuations corresponding to the total $\sigma_{u \text {,tot }}$ as well as three frequency bands of interest: $\sigma_{u \text {,low }}$, $\sigma_{u \text {,med }}$, and $\sigma_{u \text {,high. }}$ The $\sigma_{u \text {,low }}$ represents velocity fluctuations within the infra-gravity wave band ( 90 s to $30 \mathrm{~s}$ ); the $\sigma_{u \text {,med }}$ represents motion within the wave band (30 s to 4 s), and $\sigma_{u \text {,high }}$ describes the motions associated with the short waves and the larger scale turbulence ( $4 \mathrm{~s}$ to $1 \mathrm{~s}$ ). This approach has been previously employed for wavedriven flow on reefs (Hench and Rosman 2013) and provides a useful proxy for quantifying combined motion created by waves and turbulent eddies. Our primary focus was on the medium frequency band, $\sigma_{u \text {,med, }}$ which is the proxy for velocity fluctuations due to waves and the dominant feature in the observed velocity power spectra (Appendix B: Fig. B3B).

We reasoned that corallivorous fish have four main aspects related to their attacks on a coral colony: (1) location within the lagoon, (2) identification of coral prey, (3) body orientation for attack, and (4) attack. We predicted that $\sigma_{u \text {,med }}$ would have important impacts on all four aspects of coral attacks because of the frequency of physical disruptions from water motion, and the energetic costs required to counteract these hydrodynamic forces. Additionally, while $\sigma_{u \text {,med }}$ is primarily attributed to waves, these motions are also associated with turbulence due to flow separation and eddy shedding, particularly when wave orbital excursions are longer than the length scale of coral colonies (Hench and Rosman 2013). We also predicted $\sigma_{u \text {,med }}$ would describe water motions that could enhance mass transfer in corals (Falter et al. 2004).

\section{Effects of hydrodynamics on coral growth}

We conducted our field assay to quantify effects of hydrodynamics on growth of Acropora elseyi in the austral summer (December). We transplanted A. elseyi coral nubbins to each of the five study sites (L1-L5; Fig. 
1) to test the influence of hydrodynamics and corallivory on coral growth. Coral nubbins were similar in size and shape to juvenile coral colonies. See Appendix C for details about the coral transplanting procedure. Partial predation by corallivores reduces growth of acroporid and other branching corals (Lenihan et al. 2011). Accordingly, we explored the effect of corallivory on performance of transplanted nubbins. To do this, we manipulated the access of corallivorous fishes to coral nubbins by using cages (-predator treatment) and cage controls (+predator treatments, composed of partial cages); corals at each site were randomly assigned to treatments. Cages consisted of six-sided enclosures $(15 \times$ $15 \times 15 \mathrm{~cm})$ made of Vexar plastic (1-cm mesh size; Vexar Plastics, Los Angeles, California, USA), and cage controls were the same design but with two sides missing to allow corallivorous fishes access while exposing corals to hydrodynamic conditions similar to those within cages (Lenihan and Edmunds 2010). We used this size of predator exclusion cages and cage controls because, in a preliminary test, we observed butterflyfishes and other corallivores, especially spot-fin porcupinefish, whitespotted puffer, and the orange-striped triggerfish, biting branching corals within the cage controls, with all but the butterflyfishes leaving distinctive lesions. A no-cage treatment was not used, as prior trials revealed no difference in coral growth and intensity of corallivory on corals in cage controls vs. no-cage treatments. We also reasoned that, to control for the potential influence of mesh cages on local hydrodynamic conditions, and thus growth of transplanted nubbins, partially open cages allowed fish predation but also altered hydrodynamics in similar ways to predator exclusion cages. One replicate coral was placed in each cage or cage control by first fitting the cylindrical coral nubbin into a PVC plastic collar and then attaching the coral to the cage $(N$ $=12$ cages and $N=12$ cage controls) with cable ties at each site. One -predator and one +predator treatment were placed together on rigid wire mesh that was attached to a cinder block, which, in turn, was bolted to the seafloor. This design placed corals $\sim 35 \mathrm{~cm}$ above the seafloor. Coral skeletal growth was measured after two weeks, and is reported with the variable coral growth measured in buoyant weight scaled to colony size. Following buoyant weighing, corals were dried at $60^{\circ} \mathrm{C}$, and their tissue areas measured using the wax dipping technique (Stimson and Kinzie 1991) to normalize growth rates to area $\left(\mathrm{mg} \cdot \mathrm{cm}^{-2} \cdot \mathrm{d}^{-1}\right)$. Coral growth difference measured the difference in daily coral growth between pairs of predator treatments [(- predator) (+predator)] located on each cinder block at each site $(N$ $=12$ per site). Statistical treatment of this assay design is described in Statistical analyses.

\section{Estimation of the intensity of corallivory}

To estimate the intensity of corallivory, we assessed separately the abundance of corallivorous fishes and their per capita attack (bite) rates at each site.
Corallivore abundance measured all obligate and facultative corallivores, as recorded by the same observer (H. Lenihan), who counted fishes repeatedly along one $20 \times 4 \mathrm{~m}$ transect located at each of the five sites. Every site was surveyed on each of eight days during the assay. Of the 31 species of corallivorous fishes observed, 14 were represented by a single individual observed only once over the course of the sampling, and these 14 species were excluded from analyses. The 17 most abundant species included four species of obligate corallivores (Chaetodon bennetti, $C$. lunulatus, C. ornatissimus, and C. trifascialis) and 13 species of facultative corallivores (Arothron hispidus, Balistapus undulatus, Diodon hystrix, Pseudobalistes flavimarginatus, Heniochus chrysostomus, Chaetodon auriga, C. citrinellus, C. ephippium, C. lunula, C. mertensii, C. pelewensis, C. quadrimaculatus, and $C$. vagabundus) (based on Cole et al. 2008).

Bite rate measured the number of corallivore bites on corals, estimated during four days, by counting the number of bites taken by haphazardly selected focal chevron butterflyfish (Chaetodon trifascialis) at each site ( $N=3$ fish per site per day). This species is an obligate corallivore (Pratchett et al. 2013), was relatively abundant throughout the study area, and displayed the same general pattern of distribution across the lagoon that we observed for all corallivores, obligate corallivores, and facultative corallivores (Appendix D: Fig. D1). All sampling was conducted between 08:30 and 11:00 each day. One observer (H. Lenihan) conducted all the sampling by selecting a fish that was observed initially attacking corals, and following that fish for a 5min period, recording the number of bites taken. The diver maintained a distance of $5-8 \mathrm{~m}$, so as not to interfere with the fish's feeding activity. Data are reported as the grand means of all attack rates recorded for all 12 fish over the four-day period for each site. An index of consumer pressure for each site was generated by multiplying the mean abundance of $C$. trifascialis with the bite rate of $C$. trifascialis.

\section{Statistical analyses}

To test for covariance between mean current velocity $(\bar{u})$ and medium frequency velocity fluctuations $\left(\sigma_{u, \text { med }}\right)$ at each site, we calculated the Pearson product moment correlation coefficient between $\bar{u}$ and $\sigma_{u \text {,med }}(N=5$ corals each). We regressed coral growth against $\bar{u}$ and $\sigma_{u \text {,med }}$ separately in both the cage and cage control treatments $(N$ $=12$ corals each site) to test whether coral skeletal growth varied with hydrodynamic conditions. We regressed coral growth difference ( $N=12$ corals each site) against $\bar{u}$ and $\sigma_{u, \text { med }}$ at each site to test whether differences in -predator and +predator treatments varied with hydrodynamic conditions. Coral growth difference was regressed against (total) corallivore abundance and consumer pressure (of C. trifascialis) for each site to determine whether coral growth varied with the intensity of corallivory. We regressed total corallivore abundance, C. trifascialis 


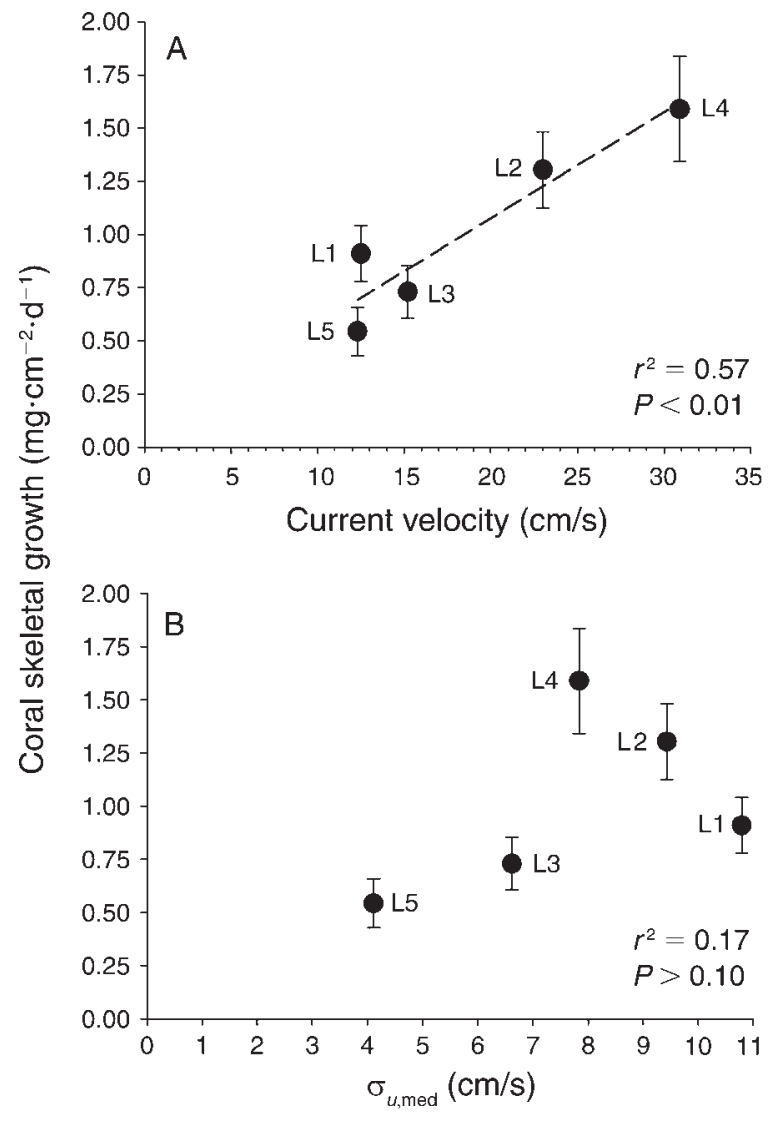

FIG. 2. Skeletal growth (mean and $95 \% \mathrm{CI}$ ) of Acropora elseyi as a function of the (A) mean current velocity and (B) velocity fluctuations ( $\sigma_{u \text {,med }}$, a measure of waves and turbulence measured at each study site; see Methods: Hydrodynamic measurements). Data are from corallivorous fish exclusion treatments (i.e., full cages; - predator). $N=12$ corals for each growth measurement. The symbols L1-L5 indicate the five study sites (see Fig. 1).

abundance, and bite rate (of C. trifascialis) against $\bar{u}$ and $\sigma_{u \text {,med }}$ separately to test whether these aspects of corallivory varied with hydrodynamic conditions. In addition, as specification checks, we conducted these tests using $\sigma_{u \text {,tot }}, \sigma_{u \text {, high }}$, and $\sigma_{u \text {, low }}$ in place of $\sigma_{u \text {,med }}$ to explore the influence of different frequencies of water motion on coral growth and corallivory. All statistical analyses were conducted in Stata 12.1 via ordinary least squares (StataCorp 2011). We used parametric tests because data were normally or approximately normally distributed. Because the data include multiple measurements across the five sites, we adjusted the standard errors to account for site-specific heteroskedasticity using Stata's robust standard errors. ANOVA was used to test whether the relationship in each regression was different from zero.

\section{Results}

\section{Patterns of hydrodynamics}

Mean velocity $(\bar{u})$ and velocity fluctuations $\left(\sigma_{u, \text { med }}\right)$ varied substantially among the five sites but their correlation did not differ from zero $(r=0.201 ; P>$ $0.10)$. Velocity was also uncorrelated with $\sigma_{u \text {,tot }}(r=$ $0.118 ; P>0.30), \sigma_{u \text {, high }}(r=0.138 ; P>0.10)$, and $\sigma_{u \text {, low }}$ $(r=0.137 ; P>0.20)$. Current velocities were very low in the back reef just behind the reef crest (site L1 $=13 \pm 2$ $\mathrm{cm} / \mathrm{s}$; mean $\pm \mathrm{SD}$ ) and also at the fringing reef site closest to shore $(\mathrm{L} 5=12 \pm 2 \mathrm{~cm} / \mathrm{s})$. They were greatest at L4 $(31[29,33] \mathrm{cm} / \mathrm{s})$ in the mid-lagoon, and lower at the other mid-lagoon sites $(\mathrm{L} 2=23[20,26] \mathrm{cm} / \mathrm{s}$ and $\mathrm{L} 3$ $=15[12,18] \mathrm{cm} / \mathrm{s})($ see Appendix B: Fig. B2A for current velocity data). Mean velocity was probably highest at L4 because the flow from a relatively large proportion of the lagoon was funneled in by the local reef topography. In contrast to mean velocity, $\sigma_{u \text {,med }}$ declined across the lagoon (see Appendix B: Fig. B2B for $\sigma_{u}$ data). Velocity fluctuations were highest just behind the reef crest ( $\mathrm{L} 1=$ $10.8 \mathrm{~cm} / \mathrm{s}$ ), where velocity was low, and lowest at the innermost site ( $\mathrm{L} 5=4.1 \mathrm{~cm} / \mathrm{s})$, with the remaining sites having intermediate values $(\mathrm{L} 2=9.4 \mathrm{~cm} / \mathrm{s}, \mathrm{L} 3=6.6 \mathrm{~cm} /$ $\mathrm{s}$, and $\mathrm{L} 4=7.8 \mathrm{~cm} / \mathrm{s}$ ). All frequency bands of velocity fluctuations showed the same trend across sites. This decrease in water velocity fluctuations across the lagoon was consistent with transformation and dissipation of incident offshore waves (Monismith et al. 2013) and drag (Rosman and Hench 2011) over rough reef topography. At sites L1 and L2, where velocity fluctuations were the greatest, hydrodynamic conditions were dominated by frequency fluctuations characteristic of passing waves and turbulent eddies. Water temperatures varied minimally across the five sites, ranging from $28.72 \pm 0.47^{\circ} \mathrm{C}$ to $28.94 \pm 0.45^{\circ} \mathrm{C}$ (mean $\left.\pm \mathrm{SD}\right)$, over the course of the study.

\section{Patterns of coral growth}

In the absence of predation, coral growth was a positive function of mean velocity $\bar{u}$ (Fig. $2 \mathrm{~A} ; r^{2}=0.57$, $\left.F_{1,4}=43.57, P<0.01\right)$. The trend in growth was positive with $\sigma_{u \text {,med }}$ when predators were absent but the relationship was not statistically distinguishable from zero (Fig. $2 \mathrm{~B} ; r^{2}=0.17, F_{1,4}=2.36, P>0.10$ ). Linear regressions also revealed no significant relationships between coral growth in the absence of predators and $\sigma_{u \text {,tot }}\left(r^{2}=0.12, F_{1,4}=1.54, P>0.10\right), \sigma_{u \text {,high }}\left(r^{2}=0.06\right.$, $\left.F_{1,4}=0.62, P>0.10\right)$, and $\sigma_{u \text { low }}\left(r^{2}=0.12, F_{1,4}=1.73, P\right.$ $>$ 0.10). By contrast, patterns in the +predator treatments varied substantially from those in the -predator treatments. When corals were exposed to corallivores, coral growth was not significantly related to current velocity (Fig. $3 \mathrm{~A} ; r^{2}=0.19, F_{1,4}=2.38, P>$ $0.10)$. Instead, coral growth in the presence of predators was positively related to $\sigma_{u \text {,med }}$ and the relationship was statistically significant (Fig. $3 \mathrm{~B} ; r^{2}=0.60, F_{1,4}=11.39, P$ $<0.03)$.

The observed gradient of likely effects of corallivory on coral growth (i.e., coral growth difference) was unrelated to mean current velocities (Fig. 4A; $r^{2}=0.004$; $\left.F_{1,4}=0.03, P>0.50\right)$, but was related negatively to $\sigma_{u, \text { med }}$ (Fig. 4B; $r^{2}=0.50, F_{1,4}=45.79, P<0.01$ ). Coral 


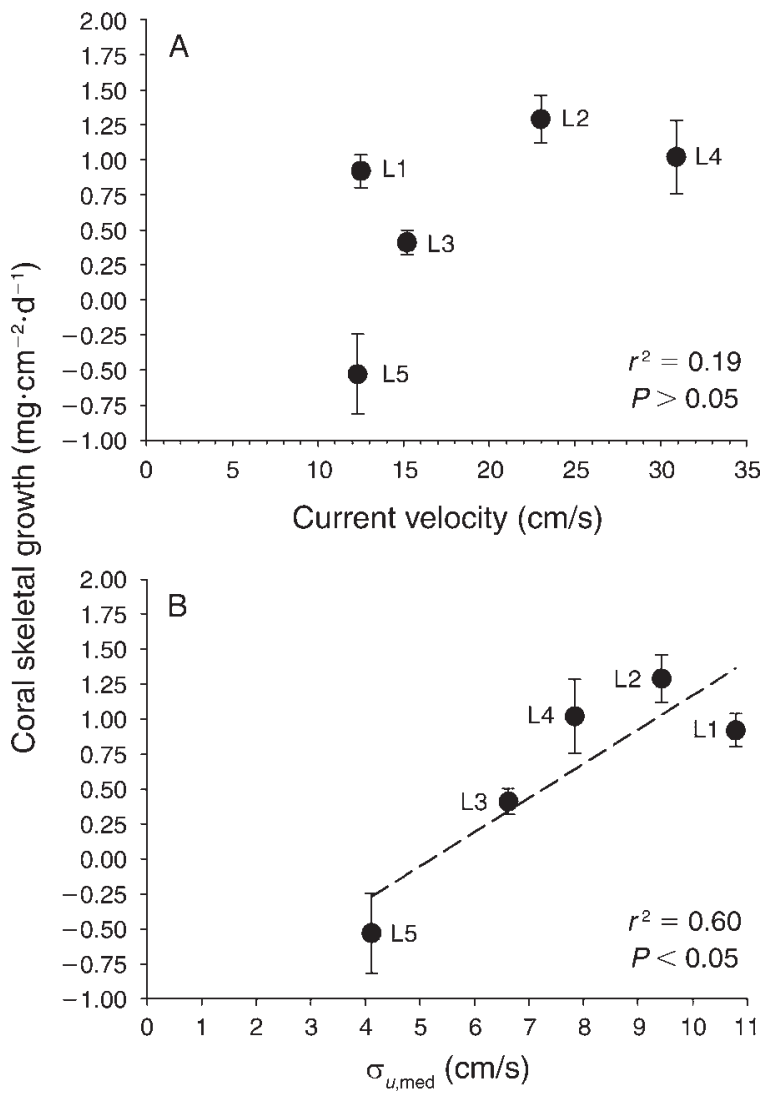

FIG. 3. Skeletal growth (mean and $95 \% \mathrm{CI}$ ) of Acropora elseyi exposed to predators shown as a function of the (A) mean current velocity and (B) velocity fluctuations $\left(\sigma_{u \text {,med }}\right)$. Data are from corallivorous fish exclusion cage control treatments (i.e., partial cages; +predator). The symbols L1-L5 indicate the five study sites (see Fig. 1).

growth difference was almost zero at the two highest levels of $\sigma_{u \text {,med }}$ (L1-L2), near the barrier reef crest where there was no apparent predation on corals. By contrast, there was quite a large difference in growth between cage treatments at the lowest level of velocity fluctuations, closer to shore (L5), where corallivores removed a substantial amount of tissue causing loss of coral biomass in +predator treatments.

The across-lagoon (i.e., cross-reef) gradient in coral growth difference increased with corallivore abundance (i.e., mean abundance of all corallivores) from offshore (back reef L1) to nearshore (fringing reef L5), and explained $52 \%$ of the among-site variation in growth reduction of corals exposed to predators (Fig. $5 \mathrm{~A} ; r^{2}=$ $\left.0.52, F_{1,4}=24.36, P<0.01\right)$. The gradient in coral growth difference also increased with our index of corallivore consumer pressure (i.e., the abundance of chevron butterflyfishes multiplied by their bite rates) from L1 to L5 (Fig. 5B). Consumer pressure explained $53 \%$ of the among-site variation in growth reduction of corals exposed to predators $\left(r^{2}=0.53, F_{1,4}=493.33, P<\right.$ $0.0001)$. The relatively tight, linear coupling with both total corallivore abundance and our index of consumer pressure strengthens our confidence that the difference in coral growth between the +predator and -predator treatments at a site can be attributed mainly to corallivory.

To explore the specific mechanism(s) by which hydrodynamic forces influenced corallivorous fish and their capacity to mediate coral growth, we compared separately how total corallivore abundance and per capita bite rate of $C$. trifascialis varied with mean velocity $(\bar{u})$ and velocity fluctuations $\left(\sigma_{u, \text { med }}\right)$. Variation in corallivore abundance and per capita bite rate were unrelated to differences in mean velocity (abundance, $r^{2}$ $=0.04, F_{1,4}=0.18, P>0.50$; bite rate, $r^{2}=0.09, F_{1,4}=$ $0.48, P>0.50)$. In contrast, both total corallivore abundance and bite rate declined substantially with increases in $\sigma_{u \text {,med }}$ (Fig. 6A, abundance, $r^{2}=0.77, F_{1,4}=$ 78.40, $P<0.001$; Fig. 6B, bite rate, $r^{2}=0.92, F_{1,4}=$ 400.55, $P<0.001)$. Similar regressions run with $C$. trifascialis abundance showed similar patterns (velocity, $r^{2}=0.002, F_{1,4}=0.015, P>0.50 ; \sigma_{u, \text { med }}, r^{2}=0.40, F_{1,4}=$ 83.37, $P<0.001)$.

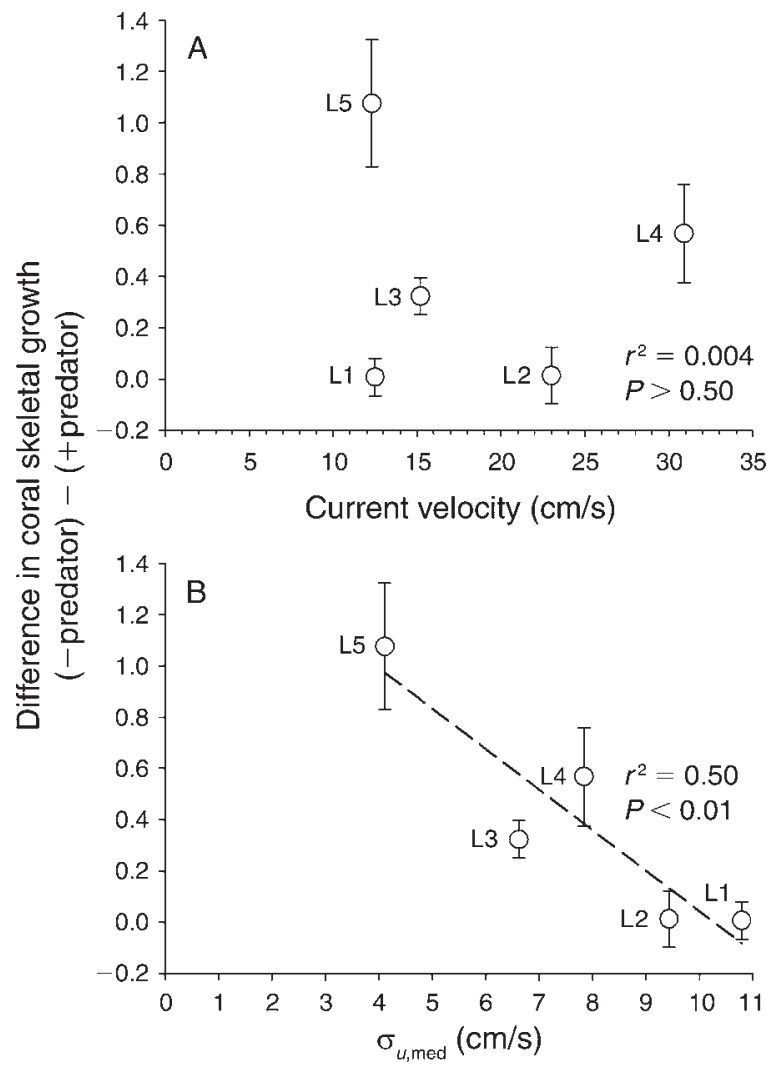

FIG. 4. Difference in growth (mean and 95\% CI) of Acropora elseyi between - predator and +predator (i.e., cage controls) treatments as a function of (A) mean current velocity and (B) the velocity fluctuations $\left(\sigma_{u \text {,med }}\right) . N=12$ corals for each difference measurement. The symbols L1-L5 indicate the five study sites (see Fig. 1). 


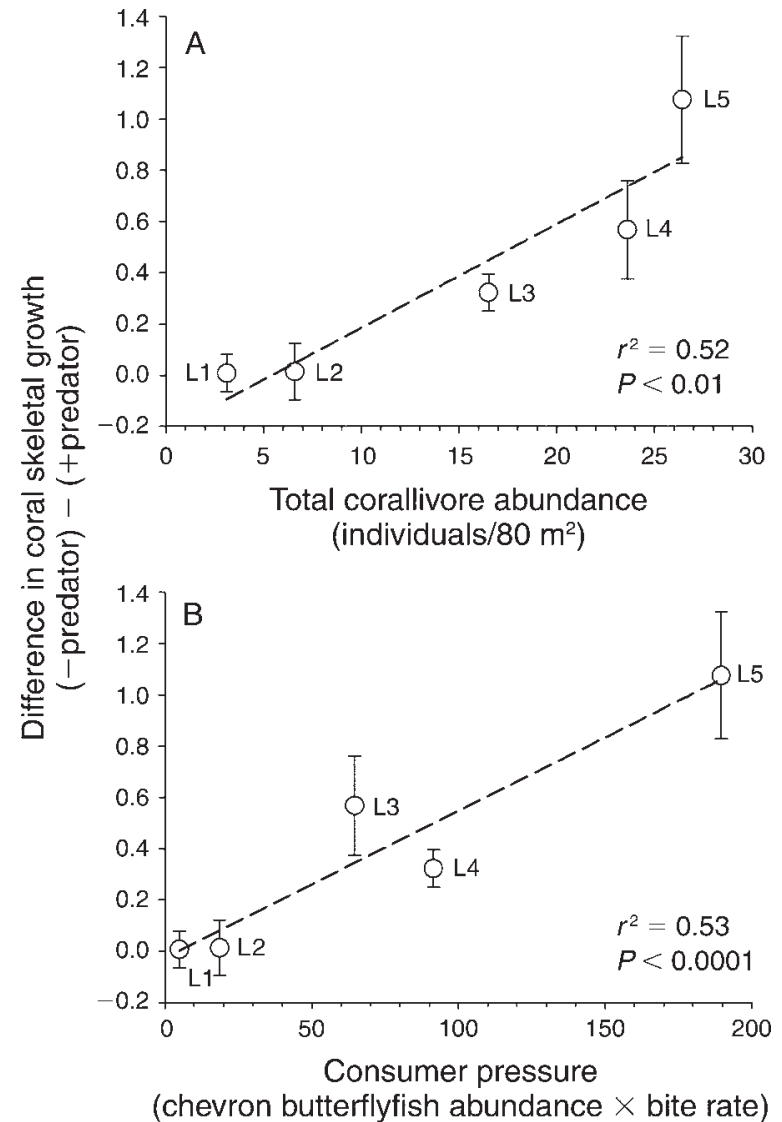

FIG. 5. Difference in growth (mean and 95\% CI) of Acropora elseyi between - predator and +predator (i.e., cage controls) treatments as a function of the density of (A) all corallivorous fishes (no. corallivores $/ 80 \mathrm{~m}^{2}$ ) and (B) consumer pressure, an index generated by multiplying the mean density of chevron butterflyfishes (Chaetodon trifascialis; no. fish/80 $\mathrm{m}^{2}$ ) by mean bite rate (no. bites $/ 5 \mathrm{~min}$ ) of individual $C$. trifascialis recorded at each site.

\section{Discussion}

In the absence of predation, growth of acroporid corals was heavily influenced by mean current velocity, potentially because of increased mass transfer and enhanced autotrophy. A previous study at this site, designed to test whether total zooplankton flux influenced corals, found no relationship between skeletal growth and particulate food flux (Alldredge et al. 2013), thereby suggesting that hydrodynamicallyenhanced autotrophy, rather than heterotrophy, was the more important factor in our study. We also observed no differences in temperature across the sites during the assay, and saw no differences in light levels in a previous study (Lenihan et al. 2008), so we cannot attribute growth differences to these often-considered factors. Differences in coral growth among treatments were also closely associated with corallivore abundance and feeding behavior. Corallivores largely avoided areas of high waves and turbulence but when they did visit wavy, turbulent sites they were heavily influenced by the oscillatory flow. Coral reef flows are complex; they vary at small spatial scales and are highly unsteady due to a combination of currents, waves, and turbulence interacting with multi-scale topographic features (Hench and Rosman 2013). Water motion that varies spatially or temporally can perturb fish by generating linear translations, changes in depth, angular rotation, body deformation, or alteration of swimming motions and trajectories (Liao 2007). While fish are well adapted to turbulent flow, fluctuations in water velocity and direction can interfere with swimming and increase the energetic cost of maintaining position (Enders et al. 2003). For the coral species and the locale we examined, the indirect effect of reducing corallivory produced $\sim 50 \%$ more coral growth (i.e., a $4 \%$ increase in daily growth rate) than that explained by the direct effects of velocity (e.g., mass transfer and autotrophy) alone.

The influence of flow velocity on predator-prey interactions in streams is well recognized (Hart and Finelli 1999, Aseada et al. 2005). Surprisingly few studies have quantified the influence of turbulence and wave-generated oscillatory flow on marine benthic
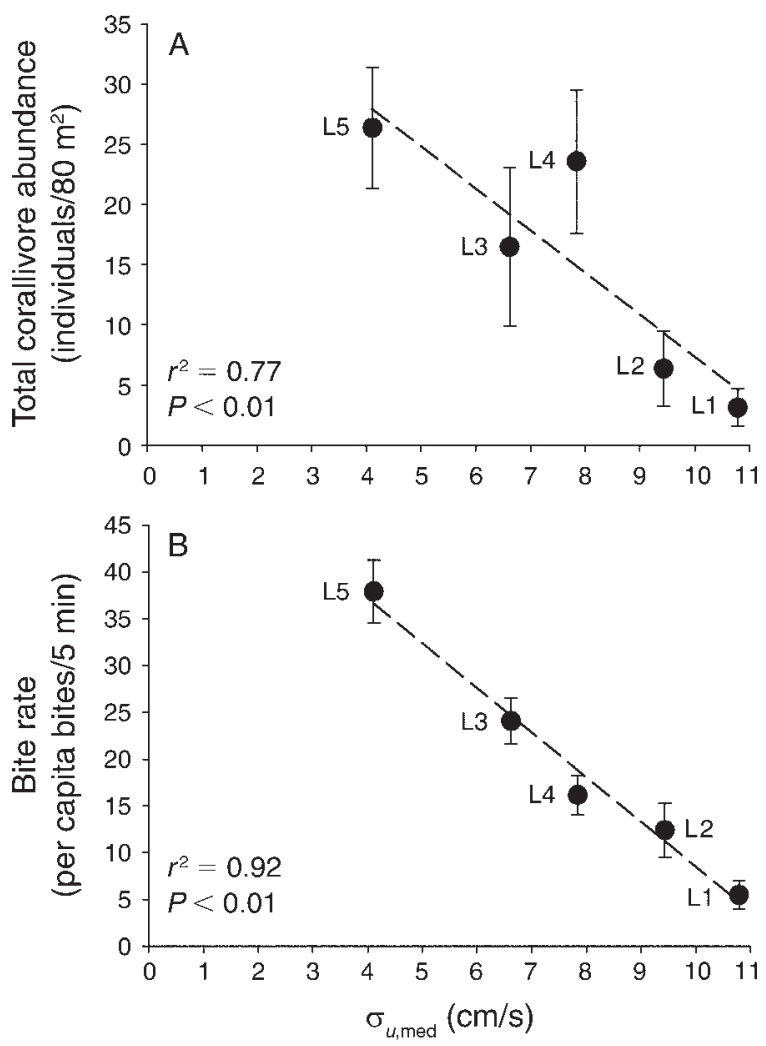

FIG. 6. (A) Density of all corallivorous fishes (no. corallivores $/ 80 \mathrm{~m}^{2}$ ) and (B) per capita bite rate of C. trifascialis as a function of $\sigma_{u \text {,med }}$, a measure of waves and turbulence. $N=$ 8 transects per site for fish density counts; $N=12$ focal fish per site for the estimation of per capita bite rates. Values are means and $95 \% \mathrm{CI}$. 


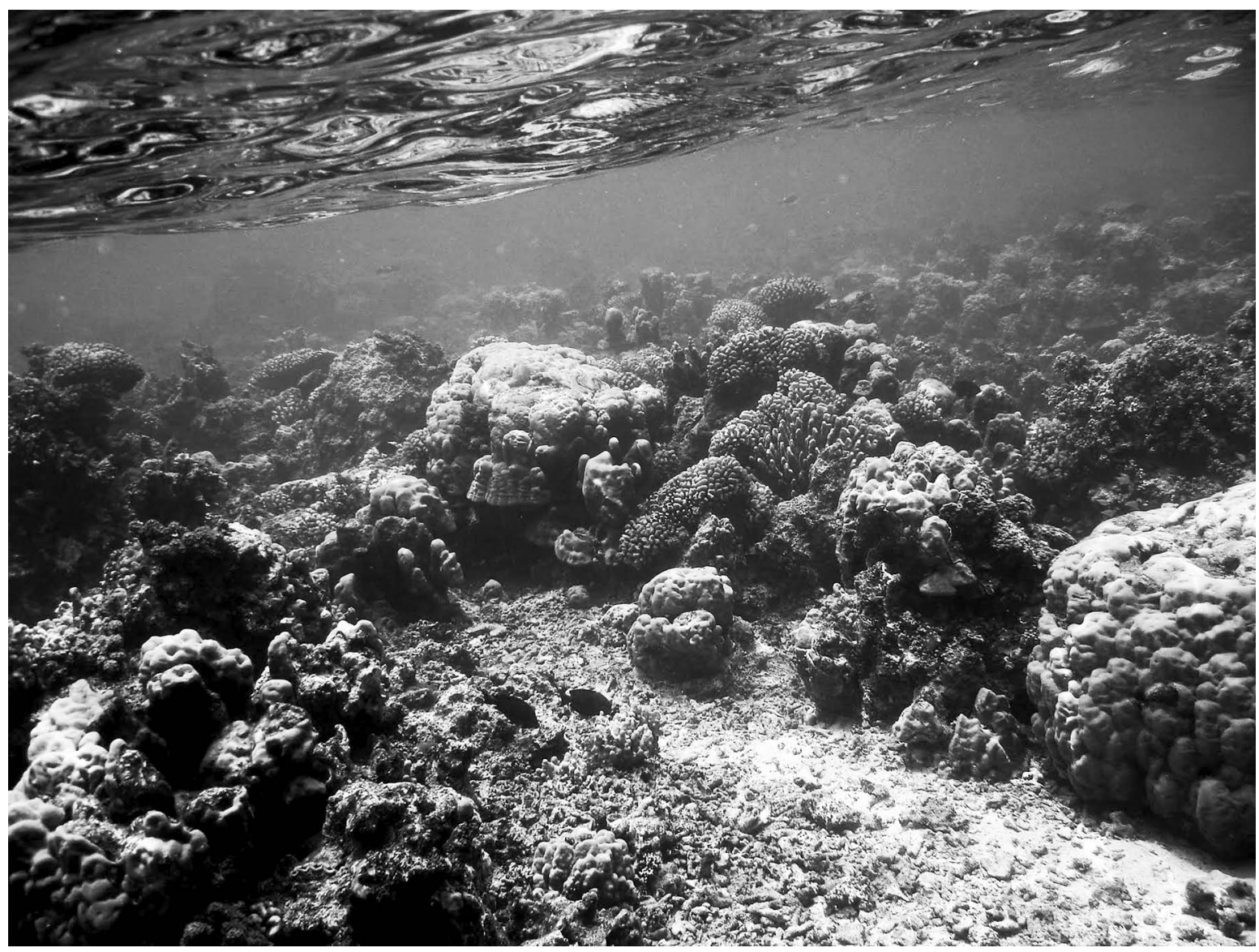

Plate 1. Wave-driven flow can mediate coral growth through direct and indirect effects. Shown here is the back reef study site on the north shore of Mo'orea, French Polynesia. Photo credit: J. L. Hench.

predator-prey interactions involving fish, despite the ubiquitous presence of turbulence and/or waves in shallow water habitats. Yet consideration of these factors provided key insight in our study. Prior work has shown that turbulence reduces the capacity of zooplanktivorous fish from capturing suspended zooplankton (Kiflawi and Genin 1997), and that turbulence interferes with olfactory-based detection of benthic prey by crabs (Smee et al. 2010) and crayfish (Moore and Grills 1999). In turbulent flow, reef fish spend a relatively large amount of time in flow energy refuges (Johansen et al. 2007, 2008). Others have examined the influences of wave motion on the swimming modes of fish assemblages (Fulton and Bellwood 2005), the composition of reef fish assemblages (Friedlander et al. 2003, Fulton and Bellwood 2004, Fulton et al. 2005), the zonation of prey species attributed to the negative effects of wave energy on benthic predators, especially sea stars, crabs, and spiny lobsters (Leonard et al. 1998, Robles et al. 2001), and the simultaneous direct (displacement) and indirect effects (habitat structuring) of wave exposure on the distribution and abundance of cryptobenthic reef fishes (Santin and Willis 2007). Here we provide the first quantitative estimates of the direct effects of velocity on individual performance of a prey species, while simultaneously estimating the concurrent indirect effects of waves and turbulence as forces that reduce predator abundance and feeding activity. We found little relationship between the response of corals to predators and mean velocity (Fig. 3A). Instead, differences among the -predator and +predator treatments varied largely as a function of velocity fluctuations, as did the density of corallivores and attack rates (Figs. 5 and 6). These results imply that corallivores largely avoid high wave and turbulence areas, but when they do not, they are physically less capable of attacking corals. They may also alter their behavior and reduce their feeding activity by restricting attacks to short periods when the energy of waves and turbulent eddies are relatively low, such as during lulls between wave groups. During turbulent periods they may hide in physical refuges to save energy (Johansen et al. 2008).

Further detailed study of the role of hydrodynamics will help us meet the challenge of forecasting community dynamics and generate a better understanding of the interplay among hydrodynamic conditions, habitat structure, and biotic interactions at a landscape scale. Our findings underscore the importance of physical- 
biological interactions that affect juveniles, the understanding of which is fundamental to our ability to predict the trajectory of community recovery from large-scale disturbances. Future efforts to restore branching acroporids should carefully consider hydrodynamic conditions across reefscapes to both enhance the direct delivery of nutrients and indirect effect of reducing corallivory.

\section{ACKNOWLEDGMENTS}

We thank O. Lenihan, R. Lenihan, J. Rosman, M. Schmitt, K. Seydel, J. Yousing, and T. Yousing for help in the field and laboratory. The study was supported by NSF through the Mo'orea Coral Reef LTER (OCE0417412, OCE1026851; OCE1236905) and Physical Oceanography (OCE0622967; OCE1435133) programs, and, the Gordon and Betty Moore Foundation. It is contribution no. 207 of the UC Berkeley Gump Research Station. This paper is dedicated to the memory of Professor Marlin J. Atkinson.

\section{Literature Cited}

Adam, T. C., A. J. Brooks, S. J. Holbrook, R. J. Schmitt, P. J. Edmunds, L. Washburn, and G. Bernardi. 2014. How will coral reef fish communities respond to climate-driven disturbances? Insight from landscape-scale perturbations. Oecologia 176:285-296.

Adam, T. C., R. J. Schmitt, S. J. Holbrook, A. J. Brooks, P. J. Edmunds, R. C. Carpenter, and G. Bernardi. 2011. Herbivory, connectivity, and ecosystem resilience: response of a coral reef to a large-scale perturbation. PLOS ONE 6: e23717.

Adjeroud, M., F. Michonneau, P. J. Edmunds, Y. Chancerelle, T. Lison De Loma, L. Penin, L. Thibaut, J. Vidal-Dupiol, B. Salvat, and R. Galzin. 2009. Recurrent disturbances, recovery trajectories, and resilience of coral assemblages on a South Central Pacific reef. Coral Reefs 28:775-780.

Alldredge, A. L., S. J. Holbrook, R. J. Schmitt, A. J. Brooks, and H. Stewart. 2013. Can in situ mesozooplankton enrichment enhance skeletal growth of four scleractinian corals? Marine Ecology Progress Series 489:143-153.

Aronson, R. B., I. G. MacIntyre, S. A. Lewis, and N. L. Hilbun. 2005. Emergent zonation and geographic convergence of coral reefs. Ecology 86:2586-2600.

Aronson, R. B., and W. F. Precht. 1997. Stasis, biological disturbance, and community structure of a Holocene coral reef. Paleobiology 23:326-346.

Aseada, T., T. K. Vu, and J. Manatunge. 2005. Effects of flow velocity on feeding behaviour and microhabitat selection of the Stone Moroko Pseudorasbora parva: a trade-off between feeding and swimming costs. Transactions of the American Fishery Society 134:537-547.

Bellwood, D. R., T. P. Hughes, C. Folke, and M. Nyström. 2004. Confronting the coral reef crisis. Nature 429:827-833.

Brooks, A. 2014. MCR LTER: coral reef: long-term population and community dynamics: fishes. Mo'orea Coral Reef LTER. http://dx.doi.org/10.6073/pasta/f4b8c39f5c71493d32ede71b6 d5b503d

Brown, B. E. 1997. Adaptations of reef corals to physical environmental stress. Advances in Marine Biology 31:222301.

Cole, A. J., M. S. Pratchett, and G. P. Jones. 2008. Diversity and functional importance of coral-feeding fishes on tropical coral reefs. Fish and Fisheries 9:286-307.

De'ath, G., K. E. Fabricius, H. Sweatman, and M. Puotinen. 2012. The 27-year decline of coral cover on the Great Barrier Reef and its causes. Proceedings of the National Academy of Sciences USA 109:17995-17999.
Done, T. J. 1982. Patterns in the distribution of coral communities across the central Great Barrier Reef. Coral Reefs 1:95-107.

Enders, E. C., D. Boisclair, and A. G. Roy. 2003. The effect of turbulence on the cost of swimming for juvenile Atlantic salmon (Salmo salar). Canadian Journal of Fisheries and Aquatic Science 60:1149-1160.

Falter, J. L., M. J. Atkinson, and M. A. Merrifield. 2004. Mass-transfer limitation of nutrient uptake by a wavedominated reef flat community. Limnology and Oceanography 49:1820-1831.

Friedlander, A. M., E. K. Brown, P. L. Jokiel, W. R. Smith, and K. S. Rogers. 2003. Effects of habitat, wave exposure, and marine protected area status on coral reef fish assemblages in the Hawaiian archipelago. Coral Reefs 22: 291-305.

Fulton, C. J., and D. R. Bellwood. 2004. Wave exposure, swimming performance, and the structure of tropical and temperate reef fish assemblages. Marine Biology 144:429437.

Fulton, C. J., and D. R. Bellwood. 2005. Wave-induced water motion and the functional implications for coral reef fish assemblages. Limnology and Oceanography 50:255-264.

Fulton, C. J., D. R. Bellwood, and P. C. Wainwright. 2005. Wave energy and swimming performance shape coral reef fish assemblages. Proceedings of the Royal Society B 272: 827-832.

Glynn, P. W. 1990. Feeding ecology of selected coral-reef macro-consumers: patterns and perspectives on coral community structure. Pages 365-400 in Z. Dubinsky, editor. Ecosystems of the world 25: coral reefs. Elsevier, Amsterdam, The Netherlands.

Hart, D. D., and C. M. Finelli. 1999. Physical-biological coupling in streams: the pervasive effects of flow on benthic organisms. Annual Review of Ecology and Systematics 30: 363-395.

Hearn, C. J. 1999. Wave-breaking hydrodynamics within coral reef systems and the effect of changing relative sea level. Journal of Geophysical Research: Oceans (1978-2012) 104(C12):30007-30019.

Hench, J. L., J. J. Leichter, and S. G. Monismith. 2008. Episodic circulation and exchange in a wave-driven coral reef and lagoon system. Limnology and Oceanography 53:26812694.

Hench, J. L., and J. H. Rosman. 2013. Observations of spatial flow patterns at the coral colony scale on a shallow reef flat. Journal of Geophysical Research (Oceans) 118:1142-1156.

Hixon, M. A. 1997. Effects of reef fishes on corals and algae. Pages 230-248 in C. Birkeland, editor. Life and death of coral reefs. Chapman and Hall, New York, New York, USA.

Holbrook, S. J., A. J. Brooks, and R. J. Schmitt. 2003. Variation in structural attributes of patch-forming corals and in patterns of abundance of associated fishes. Marine and Freshwater Research 53:1045-1053.

Holbrook, S. J., R. J. Schmitt, and A. J. Brooks. 2011. Indirect effects of species interactions on habitat provisioning. Oecologia 166:739-749.

Hughes, T. P. 1994. Catastrophes, phase shifts, and large-scale degradation of a Caribbean coral reef. Science 265:15471551.

Hughes, T. P., N. A. Graham, J. B. C. Jackson, P. J. Mumby, and R. S. Steneck. 2010. Rising to the challenge of sustaining coral reef resilience. Trends in Ecology and Evolution 25: 633-642.

Jackson, J. B. C. 1992. Pleistocene perspectives on coral reef community structure. American Zoologist 32:719-731.

Johansen, J. L., D. R. Bellwood, and C. J. Fulton. 2008. Coral reef fishes exploit flow refuges in high-flow habitats. Marine Ecology Progress Series 360:219-226. 
Johansen, J. L., C. J. Fulton, and D. R. Bellwood. 2007. Avoiding the flow: refuges expand the swimming potential of coral reef fishes. Coral Reefs 26:577-583.

Johnson, M. K., S. J. Holbrook, R. J. Schmitt, and A. J. Brooks. 2011. Fish communities on staghorn coral: effects of habitat characteristics and resident farmerfishes. Environmental Biology of Fishes 21:429-448.

Jokiel, P. L. 1978. Effects of water motion on reef corals. Journal of Experimental Marine Biology and Ecology 35:8797.

Kiflawi, M., and A. Genin. 1997. Prey flux manipulation and the feeding rates of reef-dwelling planktivorous fish. Ecology 78:1062-1077.

Knowlton, N., J. C. Lang, and B. D. Keller. 1990. Case study of natural population collapse: post-hurricane predation on Jamaican staghorn corals. Smithsonian Contributions to the Marine Sciences 31:1-25.

Lenihan, H. S., M. Adjeroud, M. J. Kotchen, J. L. Hench, and T. Nakamura. 2008. How reef structure regulates small-scale spatial variation in coral bleaching. Marine Ecology Progress Series 370:127-141.

Lenihan, H. S., and P. J. Edmunds. 2010. Response of Pocillopora verrucosa to corallivory varies with environmental conditions. Marine Ecology Progress Series 409:51-63.

Lenihan, H. S., S. J. Holbrook, R. J. Schmitt, and A. J. Brooks. 2011. Influence of corallivory, competition, and habitat structure on coral community shifts. Ecology 92:1959-1971.

Leonard, G. H., J. M. Levine, P. R. Schmidt, and M. D. Bertness. 1998. Flow-driven variation in intertidal community structure in a Maine estuary. Ecology 79:1395-1411.

Lesser, M. P., V. M. Weis, M. R. Patterson, and P. L. Jokiel. 1994. Effects of morphology and water motion on carbon delivery and productivity in the reef coral, Pocillopora damicornis (Linnaeus): diffusion barriers, inorganic carbon limitation, and biochemical plasticity. Journal of Experimental Marine Biology and Ecology 178:53-179.

Liao, J. C. 2007. A review of fish swimming mechanics and behavior in altered flow. Philosophical Transactions of the Royal Society B 362:1973-1993.

Littler, M. M., P. R. Taylor, and D. S. Littler. 1989. Complex interactions in the control of coral zonation on a Caribbean reef flat. Oecologia 80:331-340.

Madin, J. S., and S. R. Connolly. 2006. Ecological consequences of major hydrodynamic disturbances on coral reefs. Nature 444:477-480.

Miller, M. W., and M. E. Hay. 1998. Effects of fish predation and seaweed competition on the survival and growth of corals. Oecologia 113:231-238.

Monismith, S. G., L. M. M. Herdman, S. H. Ahmerkamp, and J. L. Hench. 2013. Wave transformation and wave-driven flow across a steep coral reef. Journal of Physical Oceanography 43:1356-1379.

Moore, P. A., and J. L. Grills. 1999. Chemical orientation to food by the crayfish Orconectes rusticus: influence of hydrodynamics. Animal Behaviour 58:953-963.
Moran, P. J. 1986. The Acanthaster phenomenon. Oceanography and Marine Biology 24:379-480.

Mumby, P. J., and R. S. Steneck. 2008. Coral reef management and conservation in light of rapidly evolving ecological paradigms. Trends in Ecology and Evolution 23:555-563.

Neudecker, S. 1979. Effect of grazing and browsing fishes on the zonation of corals in Guam. Ecology 60:666-672.

Powers, S. P., and J. N. Kittinger. 2002. Hydrodynamic mediation of predator-prey interactions: differential patterns of prey susceptibility and predator success explained by variation in water flow. Journal of Experimental Marine Biology and Ecology 273:171-187.

Pratchett, M. S., N. A. J. Graham, and A. J. Cole. 2013. Specialist corallivores dominate butterflyfish assemblages in coral-dominated reef habitats. Journal of Fish Biology 82: 1177-1191.

Robles, C. D., M. A. Alvarado, and R. A. Desharnais. 2001. The shifting balance of littoral predator-prey interaction in regimes of hydrodynamic stress. Oecologia 128:142-152.

Rosman, J. H., and J. L. Hench. 2011. A framework for understanding drag parameterizations for coral reefs. Journal of Geophysical Research (Oceans) 118:1142-1156.

Rotjan, R. D., J. L. Dimond, D. J. Thornhill, J. J. Leichter, B. Helmuth, D. W. Kemp, and S. M. Lewis. 2006. Chronic parrotfish grazing impedes coral recovery after bleaching. Coral Reefs 25:361-368.

Rotjan, R. D., and S. M. Lewis. 2008. Impact of coral predators on tropical reefs. Marine Ecology Progress Series 367:73-91.

Santin, S., and T. J. Willis. 2007. Direct versus indirect effects of wave exposure as a structuring force on temperate cryptobenthic fish assemblages. Marine Biology 151:16831694.

Sebens, K., B. Helmuth, E. Carrington, and B. Agius. 2003. Effects of water flow on growth and energetics of the scleractinian coral Agaricia tenuifolia in Belize. Coral Reefs 22:35-47.

Smee, D. L., M. C. Ferner, and M. J. Weissburg. 2010. Hydrodynamic sensory stressors produce nonlinear predation patterns. Ecology 91:1391-1400.

StataCorp. 2011. Stata statistical software: release 12. StataCorp, College Station, Texas, USA.

Stimson, J., and R. A. Kinzie. 1991. The temporal pattern and rate of release of zooxanthellae from the reef coral Pocillopora damicornis (Linnaeus) under nitrogen enrichment and control conditions. Journal of Experimental Marine Biology and Ecology 153:63-74.

Trapon, M. L., M. S. Pratchett, and L. Penin. 2011. Comparative effects of different disturbances in coral reef habitats in Mo'orea, French Polynesia. Journal of Marine Biology 2011:Article ID 807625.

Veron, J. E. N. 2000. Corals of the world. Volume 1. Australian Institute of Marine Sciences, Townsville, Australia.

Wellington, G. M. 1982. Depth zonation of corals in the Gulf of Panama: control and facilitation by resident reef fishes. Ecological Monographs 52:223-241.

\section{Supplemental Material}

\section{Ecological Archives}

Appendices A-D are available online: http://dx.doi.org/10.1890/14-1115.1.sm 


\section{Appendix A. Description of Moorea's lagoon, details of the biotic and abiotic attributes of the reefscape, details of sampling sites, and position of sampling sites.}

The lagoon bottom in Mo'orea, French Polynesia is a patchy mosaic of substrates (coral rubble, sand, and basalt bottom) interspersed with coral colonies ranging in diameter from several $\mathrm{mm}$ to several $\mathrm{m}$. Detailed descriptions of the physical structure, geomorphology, hydrology, and hydrodynamics of the biozones within Mo'orea's lagoons are published elsewhere (Galzin and Pointier 1985, Hench et al. 2008, Lenihan et al. 2011). Juvenile and adult branching corals, predominantly Pocillopora spp. and Acropora spp., are found in greatest abundance in the back reef biozone that experiences the highest amount of wave energy and current velocity. These coral genera also are the most common branching corals on the fore reef (i.e., outside of the lagoon). Mounding and massive poritid corals (Porites lobata, P. australiensis, P. lutea, and $P$. rus) are distributed evenly across the three major lagoon habitats, back reef, mid-lagoon, and fringing reef but are also found on the fore reef. Large colonies ( $\leq 2 \mathrm{~m}$ tall and $4 \mathrm{~m}$ in diameter) of dead or partially dead poritid corals ("bommies") provide substrate used by other species of corals, as well as invertebrates, algae, and fishes (Munday et al. 1997) for recruitment (Norström et al. 2007) and refuge from predators (Holbrook et al. 2011). Moorea's back reef and midlagoon habitats support relatively large populations of many corallivorous fishes, especially butterflyfishes (Chaetodontidae), porcupinefish (Diodon hystrix; Diodontidae), white-spotted puffers (Arothron hispidus; Tetradontidae), and several species of triggerfish (Balistidae) (Brooks 2014).

Study sites L1-L5 were situated from 45 to $670 \mathrm{~m}$ from the reef crest at depths of 1.7 to $3 \mathrm{~m}$. They encompassed a large hydrodynamic gradient, from the energetic reef crest (i.e., site L1) to the relatively quiescent mid-lagoon (site L5). Cross-reef hydrodynamic gradients are generated by offshore waves that break over the reef crest and drive persistent flow across the reef flat and through lagoons (Hench et al. 2008; Monismith et al. 2013). All of the sites had nearby bommies of different sizes, but specific locations for coral transplants and hydrodynamic measurements were separated from bommies $>20 \mathrm{~cm}$ in height by at least $5 \mathrm{~m}$. Sediment deposition over time scales less than several months varied little among the five locations (Lenihan et al. 2011).

\section{Literature Cited}

Brooks, A. 2014. MCR LTER: Coral Reef: Long-term Population and Community Dynamics: Fishes. Moorea Coral Reef LTER. DOI: 0.6073/pasta/f4b8c39f5c71493d32ede71b6d5b503d

Galzin, R., and J. P. Pointier. 1985. Moorea Island, Society Archipelago. Proceedings of the 5th Coral Reef Symposium 1:73-102.

Hench, J. L., J. J. Leichter, and S. G. Monismith. 2008. Episodic circulation and exchange in a wave-driven coral reef and lagoon system. Limnology and Oceanography 53:2681-2694.

Holbrook, S. J., R. J. Schmitt, and A. J. Brooks. 2011. Indirect effects of species interactions on habitat provisioning. Oecologia 166:739-749. 
Lenihan, H. S., S. J. Holbrook, R. J. Schmitt, and A. J. Brooks. 2011. Influence of corallivory, competition, and habitat structure on coral community shifts. Ecology 92:1959-1971.

Monismith, S. G., L. M. M. Herdman, S. H. Ahmerkamp, and J. L. Hench. 2013. Wave transformation and wave-driven flow across a steep coral reef. Journal of Physical Oceanography 43:1356-1379.

Munday, P. L., G. P. Jones, and M. J. Caley. 1997. Habitat specialization and the distribution and abundance of coral-dwelling gobies. Marine Ecology Progress Series 152:227-239.

Norström, A. V., J. Lokrantz, M. Nyström, M., H. T. Yap. 2007. Influence of dead coral substrate morphology on patterns of juvenile coral distribution. Marine Biology 150:1145-1152. 


\section{APPENDIX B. Hydrodynamic measurements and analyses}

The five study sites in our model lagoon ecosystem experienced persistent cross-reef flow in the offshore to onshore direction due to the momentum input from offshore waves. An Acoustic Doppler Current Profiler (ADCP) was deployed at each of the five sites along this gradient. Each instrument was mounted to a flat PVC plate secured to the underlying coral pavement using stainless steel bolts epoxied into the substrate. All five ADCPs were deployed simultaneously and continuously for 56 days (December 11, 2006 to February 5, 2007) but our analyses are based on data collected over the two-week period when the coral growth and predation measurements were made (December 13-27, 2006). The ADCPs were programmed to burst sample every hour at $2 \mathrm{~Hz}$, collecting and recording 2048 velocity measurements of the bottom $0.75-\mathrm{m}$ of the water column.

The current profilers measured three velocity components $(u, v$, and $w)$ and prior to further analyses we examined the relative contributions of each component. At each site the velocity data were rotated into the principal axes of flow direction (Emery and Thomson 2001), corresponding to across-reef, along-reef, and vertical velocities. At all sites, the across-reef velocity component contributed $>95 \%$ of the total velocity (Fig. B1). The strong directional dominance is due to the simple geometry of the reef flat, small astronomical tides, and since refraction of offshore waves causes the incident wave crests to be nearly shore parallel prior to breaking. Moreover, the offshore wave motions that propagate through to the back reef behave as "shallow water" waves (where the wavelength is large compared to the water depth, and thus have nearly flat oscillatory velocities rather than the circular wave orbits that "deep water" waves exhibit). In the interest of conciseness and to more clearly illustrate the dominant physical forcing mechanism, we only used the across-reef velocity component in the calculations below. However we note that water velocities in other reef systems may be more equally partitioned between $u, v$, and $w$. In those cases, other velocity metrics that combine these components (e.g., $u_{\mathrm{rms}}$ ) may be more appropriate.

Means and standard deviations were computed at each site for the duration of the study (Fig. B2). The record captured a range of conditions, but show persistent mean across-reef velocities with standard deviations in velocity of comparable magnitude. As water moves across the back reef, flow is disrupted by coral colonies across a range of sizes creating turbulent eddies which can also be transported shoreward in the cross-reef flow (Falter et al. 2007). Given a reef flat depth $(H)$ of $2 \mathrm{~m}$, the scale of the largest turbulent eddies $(L)$ is about $1 \mathrm{~m}$. Assuming a typical current velocity $(U)$ of $10 \mathrm{~cm} \mathrm{~s}^{-1}$ would imply a turbulent eddy turnover time scale $\left(T_{\text {turb }} \sim L / U\right)$ of $10 \mathrm{~s}$. Since a typical surface wave period $\left(T_{\text {wave }}\right)$ in Moorea is also on the order of $10 \mathrm{~s}$, the time-scales of waves and turbulence overlap. Thus, while the mean current velocity is readily quantified, there is a continuum of temporal and spatial scales within the flow such that labeling observed velocity fluctuations as "waves" or "turbulence" can be problematic (Trowbridge 1998).

Since the time-scales of waves and turbulence overlap at our field site we did not attempt to make a distinction between the two. Instead, the data were partitioned into a set of frequency bands, each representing different time-scales of across-reef velocity variability on the reef. For each hourly burst of $20482 \mathrm{~Hz}$ velocity measurements, power spectra were computed using 
Welch's averaged periodogram method (Emery and Thomson 2001) using a Hann window with $50 \%$ overlap. Hourly spectra were then ensemble averaged over the entire record (Fig. B3A).

The total variance in the cross-reef velocity was obtained by integrating the area under the mean velocity spectrum, which we used to represent the total range of motions that the corals and fish experienced during the experiment. To better understand which types of water velocity fluctuations produced by waves and turbulence most affected coral growth and corallivory, the variance was further broken down (by piecewise integration of the spectra; see below) into three frequency bands: "low", "medium", and "high", which roughly correspond to water motions in the infra gravity wave band (90-sec to $30-\mathrm{sec})$, the wave band (30-sec to 4-sec), and the frequency range associated with short waves and the largest scale turbulence (4-sec to 1-sec) on the shallow reef flat. This approach has been previously employed on wave-driven flow on reefs (Hench and Rosman 2013) and provides a useful proxy for measuring combined motion created by waves and turbulent eddies. Turbulent fluctuations on coral reefs occur at time scales less than 1-sec (Hench and Rosman 2013), but these were not resolved by our measurements.

To obtain a proxy to represent water velocity fluctuations at different time scales, the contributions to the total variance from low $(0.01<f<0.033 \mathrm{~Hz})$, medium $(0.033<f<0.25 \mathrm{~Hz})$, and high $(0.25<f<1 \mathrm{~Hz})$ frequency velocity fluctuations were computed by integrating those regions of the spectrum:

$$
\operatorname{var}_{u, f_{1} f_{2}}=\int_{f_{1}}^{f_{2}} S_{u u}(f) d f
$$

where $S_{u u}$ is the power spectrum of the cross-reef velocity, $f$ is frequency, and $\operatorname{var}_{u, f_{1} f_{2}}$ is the velocity variance in the range from frequency $f_{1}$ to $f_{2}$. If the integral is evaluated over to the entire spectrum, then $\operatorname{var}_{u, f_{1} f_{2}}$ is equal to the total variance. The integrals were evaluated numerically using a trapezoid rule. The variance for each frequency band was then converted to standard deviation, which represents the deviations in velocity from the mean flow for a given frequency band:

$$
\sigma_{u, f_{1} f_{2}}=\sqrt{\operatorname{var}_{u, f_{1} f_{2}}}
$$

with standard deviations designated as $\sigma_{u, l o w}, \sigma_{u, \text { med }}$, and $\sigma_{u, h i g h}$, each having units of $\mathrm{cm} \mathrm{s}^{-1}$ (Fig. B3B).

\section{LITERATURE CITED}

Emery, W. J., and R. E. Thomson. 2001. Data Analysis Methods in Physical Oceanography. 2nd ed. Elsevier, 638 pp.

Falter, J. L., M. J. Atkinson, R. J. Lowe, S. G. Monismith, and J. R. Koseff. 2007. Effects of nonlocal turbulence on the mass transfer of dissolved species to reef corals. Limnology and Oceanography 52:274-285.

Hench, J. L., and J. H. Rosman. 2013. Observations of spatial flow patterns at the coral colony scale on a shallow reef flat. Journal of Geophysical Research (Oceans) 118:1142-1156.

Trowbridge, J. H. 1998. On a technique for measurement of turbulent shear stress in the presence of surface waves. Journal of Atmospheric and Oceanic Technology 15:290-298. 

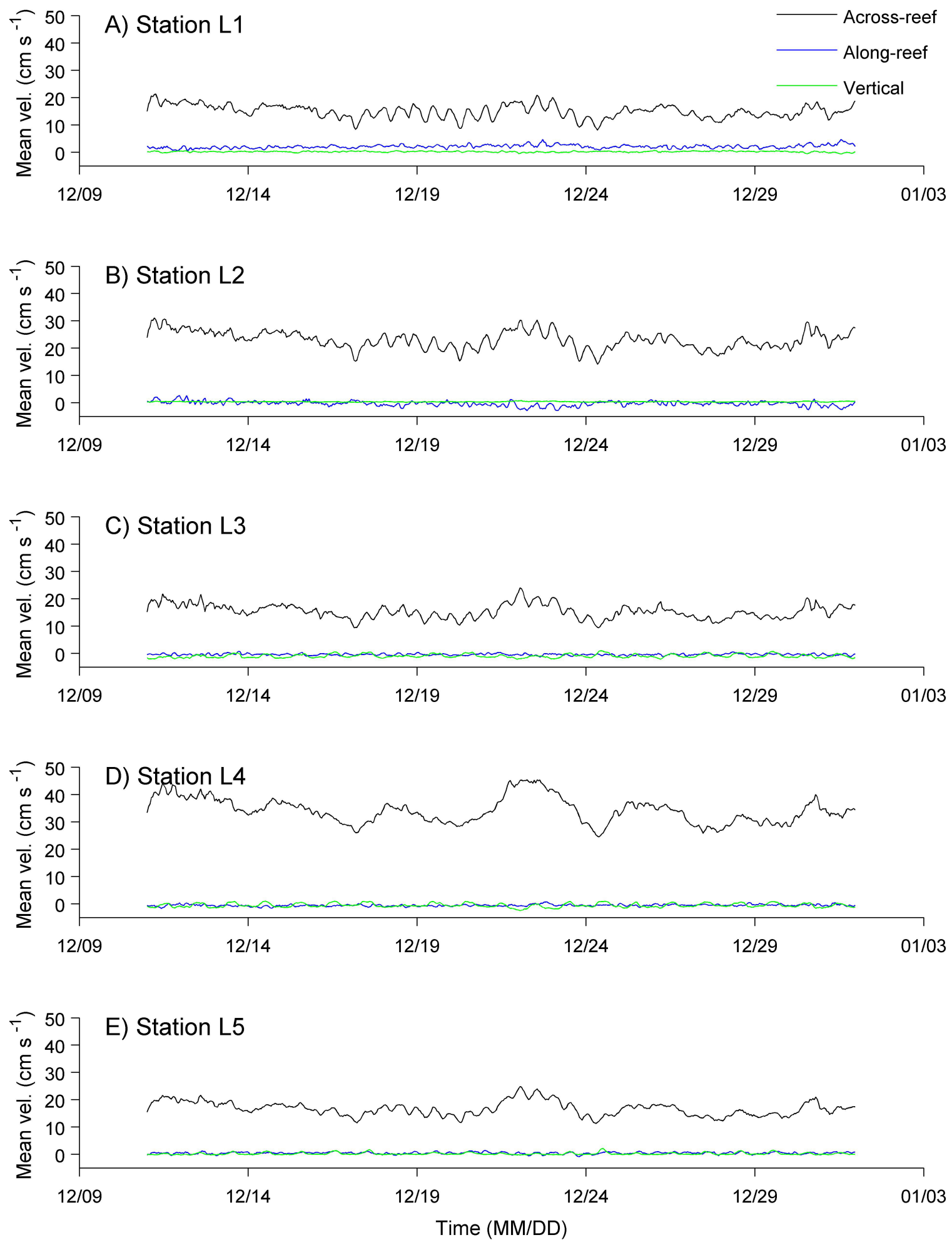

Fig. B1. Time series of water velocity components measured at five back reef sites (L1- L5). The three velocity components $(u, v$, and $w)$ have been rotated into the principal axes of flow direction (Emery and Thomson 2001), corresponding to across-reef, along-reef, and vertical velocities. 

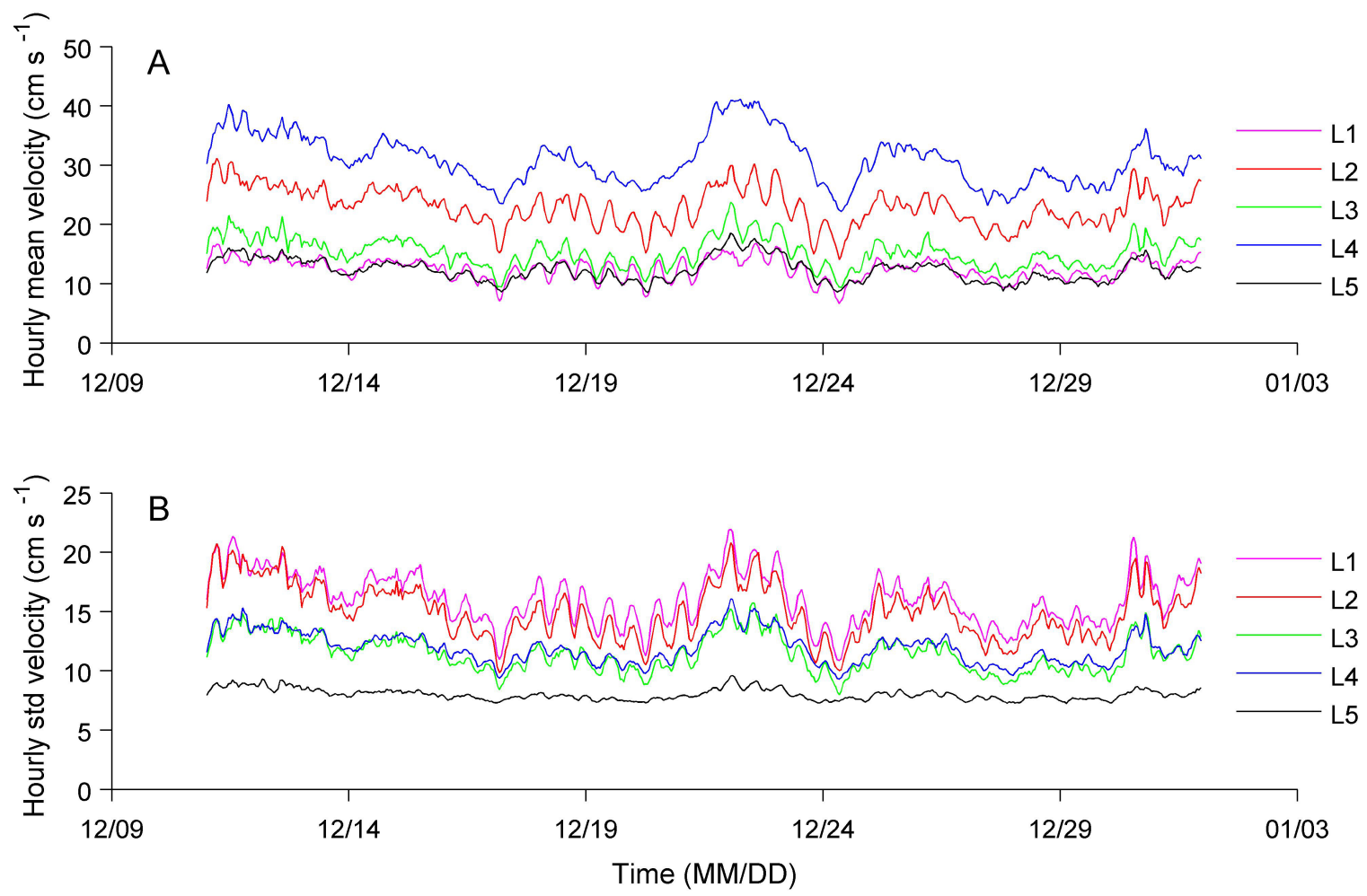

Fig. B2. Time series of water velocity measurements at five back reef sites (L1- L5). (A) Mean velocities computed from hourly bursts of 2048 measurements recorded at $2 \mathrm{~Hz}$. (B) Hourly standard deviation of velocities about the mean, computed from hourly burst samples. 

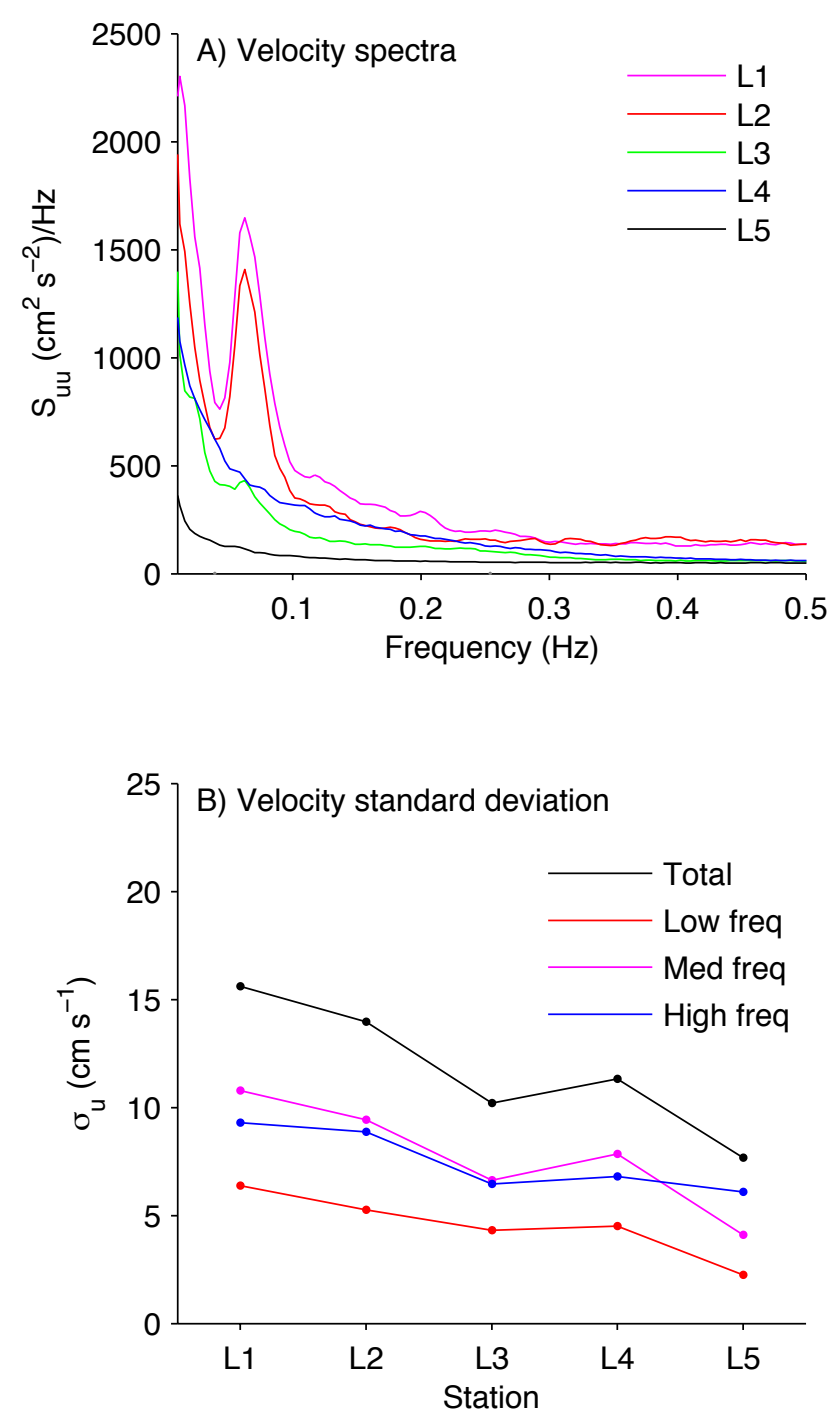

FIG. B3. Variability in across-reef velocities at each of the cross-reef coral transplant sites. (A) Power spectra computed from cross-reef velocities. Individual spectra were computed for each hourly burst, and averaged over the three-week record. (B) Velocity standard deviations $\left(\sigma_{u}\right)$ derived from power spectra shown in (A). The $\sigma_{u}$ values describing different time scales for velocity fluctuations were computed by piecewise integration of power spectrum for each frequency band (low-, medium-, and high-frequency). 


\section{APPENDIX C. Description of the coral transplanting methods.}

On 11 December 2006, near uniform-sized colony fragments ("nubbins"; 60-68 mm tall, 24-37 $\mathrm{mm}$ in diameter) were collected from several naturally-occurring donor colonies located in a nearby back reef location. Nubbins were transported in seawater to the laboratory. After $24 \mathrm{hr}$, 120 nubbins were randomly selected and buoyant weighed (Davies 1989); initial buoyant weights ranged from 3.5-9.2 gm. After an additional $24 \mathrm{hr}$, corals were outplanted by divers to sites L1-L5. (see Lenihan et al. 2011 for other details on methods).

\section{Literature Cited}

Davies, P. S. 1989. Short-term growth measurements of corals using an accurate buoyant weighing technique. Marine Biology 101:389-395.

Lenihan, H. S., S. J. Holbrook, R. J. Schmitt, and A. J. Brooks. 2011. Influence of corallivory, competition, and habitat structure on coral community shifts. Ecology 92:1959-1971. 


\section{APPENDiX D. Description of corallivorous fish assemblage, patterns of corallivore abundance in the experiment, and figure illustrating spatial variation in corallivore guilds across the sampling sites.}

Facultative and obligate corallivorous fish were counted along transects at each site (L1-L5). There were 13 species of facultative corallivores and four species of obligate corallivores, including the chevron butteflyfish (Chaetodon trifascialis), for which we counted bite rates and calculated consumer pressure (see Methods). The abundance of facultative and obligate corallivorous, as well as $C$. trifascialis, differed across sites L1-L5 but the general pattern of abundance among corallivores was similar (Fig. D1).

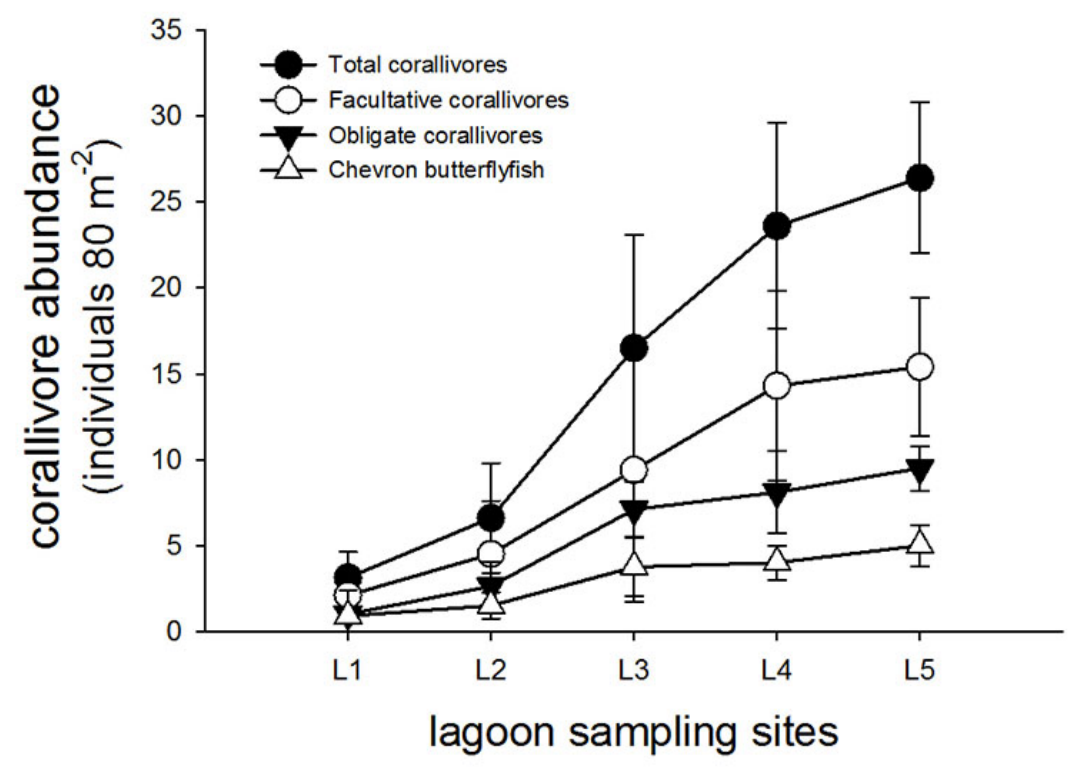

FIG. D1. Mean $( \pm 95 \% \mathrm{CI})$ density of corallivores sampled at the study sites. 